\title{
Rubiaceae no Município de Camanducaia, Serra da Mantiqueira, Minas Gerais: sinópse e chave interativa ${ }^{1}$
}

Rubiaceae in Camanducaia Municipality, Serra da Mantiqueira, Minas Gerais: synopsis and interactive key

\author{
João Afonso Martins do Carmo ${ }^{2,4}$ \& André Olmos Simões ${ }^{3}$
}

\begin{abstract}
Resumo
Este estudo teve como objetivos realizar o levantamento florístico da família no município de Camanducaia, Serra da Mantiqueira, extremo sul de Minas Gerais, onde extensos remanescentes de Mata Atlântica são encontrados, e elaborar uma Chave Interativa de Entradas Múltiplas (CIEM) para a identificação das espécies. O levantamento florístico foi realizado através de viagens de coleta e análise dos seguintes herbários: BHCB, ESA, HRCB, IAC, ICN, MBM, SP e UEC. Rubiaceae está representada em Camanducaia por 35 espécies, duas subespécies e duas variedades, classificadas em 17 gêneros. Borreria, Manettia e Psychotria foram os gêneros mais diversos (cinco espécies cada). Nove espécies, uma subespécie e uma variedade são endêmicas da Mata Atlântica. Duas espécies (Galianthe vaginata e Psychotria beyrichiana) são endêmicas da Serra da Mantiqueira e Serra do Mar. Psychotria beyrichiana é registrada pela primeira vez em Minas Gerais. Através da utilização da CIEM aqui proposta, a maioria dos táxons puderam ser identificados utilizando-se somente caracteres vegetativos.
\end{abstract}

Palavras-chave: afloramento rochoso, floresta ombrófila densa, floresta ombrófila mista, sudeste do Brasil, Xper.

\begin{abstract}
This study aimed to conduct a floristic survey on the family in the municipality of Camanducaia, Serra da Mantiqueira, southern Minas Gerais, where extensive remnants of Atlantic forest are found, and to produce an Interactive Key of Multiple Entries (IKME) for the identification of the species. The floristic survey was based on field expeditions and the analisys of the following herbaria: BHCB, ESA, HRCB, IAC, ICN, MBM, SP and UEC. Rubiaceae is represented in Camanducaia by 35 species, two subspecies and two varieties, classified in 17 genera. Borreria, Manettia and Psychotria were the most diverse genera (five species each). Nine species, one subspecies and one variety are endemic to the Atlantic forest. Two species (Galianthe vaginata e Psychotria beyrichiana) are endemic to the Serra da Mantiqueira and Serra do Mar. Psychotria beyrichiana is recorded for the first time in Minas Gerais. The utilization of the IKME here proposed made possible the identification of most of the taxa by utilizing only vegetative characters.
\end{abstract}

Key words: rocky outcrop, ombrophyllous forest, Araucaria forest, Southeastern Brazil, Xper.

\section{Introdução}

Rubiaceae é uma família cosmopolita, cuja diversidade e biomassa se concentram nos trópicos e subtrópicos (Davis et al. 2009), compreendendo ca. de 620 gêneros e mais de 13.000 espécies (Govaerts et al. 2006). No Brasil, é a quarta família mais diversa de Angiospermas, representada por 125 gêneros ( 15 endêmicos) e 1.375 espécies ( 726 endêmicas), cuja maior representatividade em domínios fitogeográficos se encontra na Amazônia (728 spp.) e Mata Atlântica (564 spp.), e nas regiões geopolíticas Norte (757 spp.) e Sudeste (579 spp.;

\footnotetext{
${ }^{1}$ Estudo financiado através de bolsa de Mestrado concedida ao primeiro autor.

${ }^{2}$ Universidade Estadual de Campinas - UNICAMP, Inst. Biologia, Depto. Biologia Vegetal, Prog. Pós-graduação em Biologia Vegetal, C.P. 6109, 13083-970, Campinas, SP, Brazil.

${ }^{3}$ Universidade Estadual de Campinas - UNICAMP, Inst. Biologia, Depto. Biologia Vegetal, C.P. 6109, 13083-970, Campinas, SP, Brazil.

${ }^{4}$ Autor para correspondência: jmartinsdocarmo@gmail.com
} 
BFG 2015). Segundo Davis et al. (2009), estas regiões estão entre as mais diversas do mundo para Rubiaceae, ocupando a $44^{\mathrm{a}}$ e $13^{\mathrm{a}}$ posições em diversidade relativa (levando-se em consideração a área), respectivamente, e, no caso da região Sudeste, a sexta em número absoluto de espécies endêmicas.

A grande diversidade da família, combinada à taxonomia complexa de táxons representativos na flora brasileira (e.g., tribos Psychotrieae e Spermacoceae; Delprete \& Jardim 2012), pode dificultar o processo de identificação de suas espécies, uma vez que chaves de identificação em floras e/ou sinópses regionais (Delprete et al. 2004; Delprete \& Cortés 2006; Jung-Mendaçolli 2007; Delprete 2010; Delprete et al. 2012), por exemplo, seguem estruturas dicotômicas rígidas e podem se tornar desatualizadas em poucos anos, devido a novos registros de espécies não tratadas até então e à impossibilidade da atualização desses tipos de publicação (Bittrich et al. 2012).

O processo de identificação a partir dessas obras passa por duas etapas, a identificação do gênero e, posteriormente, da espécie. Nas chaves de gêneros, estruturas reprodutivas são abordadas em seus primeiros passos, principalmente o número de óvulos por lóculo e/ou número de sementes por fruto, bem como a utilização de diferentes fases fenológicas em passos posteriores, o que pode impossibilitar o processo de identificação por exigirem amostras completas, portando flores e frutos. Uma das ferramentas utilizadas para minimizar estas limitações de chaves de identificação convencionais são as Chaves Interativas de Entradas Múltiplas (CIEM), que possibilitam a livre escolha de caracteres a serem analisados pelo usuário e podem ser continuamente atualizadas (Bittrich et al. 2012; Chrétiennot-Dinet et al. 2014).

A Mata Atlântica do Brasil é considerada um dos hotspots mundiais para a conservação da biodiversidade (Myers et al. 2000). Estimativas apontam para $11 \%$ de cobertura remanescente, a qual está geralmente representada por pequenos fragmentos (Ribeiro et al. 2009). Este fato é alarmante, pois, como demonstrado por Sobral \& Stehmann (2009), podemos considerar o conhecimento botânico relativo à Mata Atlântica ainda incipiente, visto que em menos de duas décadas, de 1990 a 2006, mais de 1.000 novas espécies de angiospermas deste domínio fitogeográfico foram descobertas, o que representa $42 \%$ do total descrito para o Brasil neste período.
Segundo Fiaschi \& Pirani (2009), a maioria dos estudos relacionados à biogeografia da Mata Atlântica apontam para uma separação histórica entre regiões norte e sul deste domínio fitogeográfico, cujas diferenças florísticas são corroboradas por inferências filogenéticas. Estas regiões apresentam seus limites mais ou menos coincidentes com o vale do Rio Doce, ao norte do Espírito Santo: a região norte da Mata Atlântica ocorre do Rio Grande do Norte (ca. $\left.5^{\circ} \mathrm{S}\right)$ até o norte do Espírito Santo (ca. $19^{\circ} \mathrm{S}$ ), enquanto a região sul ocorre a partir deste limite até o sul de Santa Catarina (ca. $29^{\circ}$ S), incluindo uma grande extensão ocidental de florestas sazonalmente secas no sudeste do Brasil, Paraguai oriental e província de Misiones na Argentina (Oliveira-Filho \& Fontes 2000) e a Província da Floresta de Araucaria angustifolia (Bertol.) Kuntze (Morrone 2006).

No Sudeste do Brasil, a Serra do Mar e a Serra da Mantiqueira destacam-se como extensos centros de endemismo de espécies (Prance 1982; Silva et al. 2004; Pinto-da-Rocha \& Silva 2005). A Serra da Mantiqueira destaca-se por ainda apresentar extensas áreas de vegetação nativa, principalmente em altitudes mais elevadas, onde o difícil acesso e o baixo potencial madeireiro contribuíram para sua preservação, e por isso esta região é considerada de importância biológica especial (Costa et al. 1998). As áreas protegidas desta cadeia de montanhas figuram entre as mais insubstituíveis do mundo em termos de biodiversidade (Le Saout et al. 2013), e sua proximidade com grandes centros urbanos como São Paulo e Rio de Janeiro fornecem uma oportunidade para que novos modelos de conservação e sustentabilidade sejam considerados, como o adotado nas Montanhas Adirondacks, nos Estados Unidos (Becker et al. 2013).

O município de Camanducaia situa-se na porção mineira da Serra da Mantiqueira, onde extensas áreas de vegetação nativa de Mata Atlântica ainda são encontradas, especialmente em altitudes mais elevadas. Este estudo tem como objetivos realizar o levantamento florístico da família Rubiaceae no município de Camanducaia, localizado no extremo sul do estado de Minas Gerais, e elaborar uma CIEM para a identificação de suas espécies.

\section{Material e Métodos}

Área de estudo

O município de Camanducaia localiza-se na região Sudeste do Brasil, em Minas Gerais, na divisa com o estado de São Paulo (Fig. 1a,b). Os 


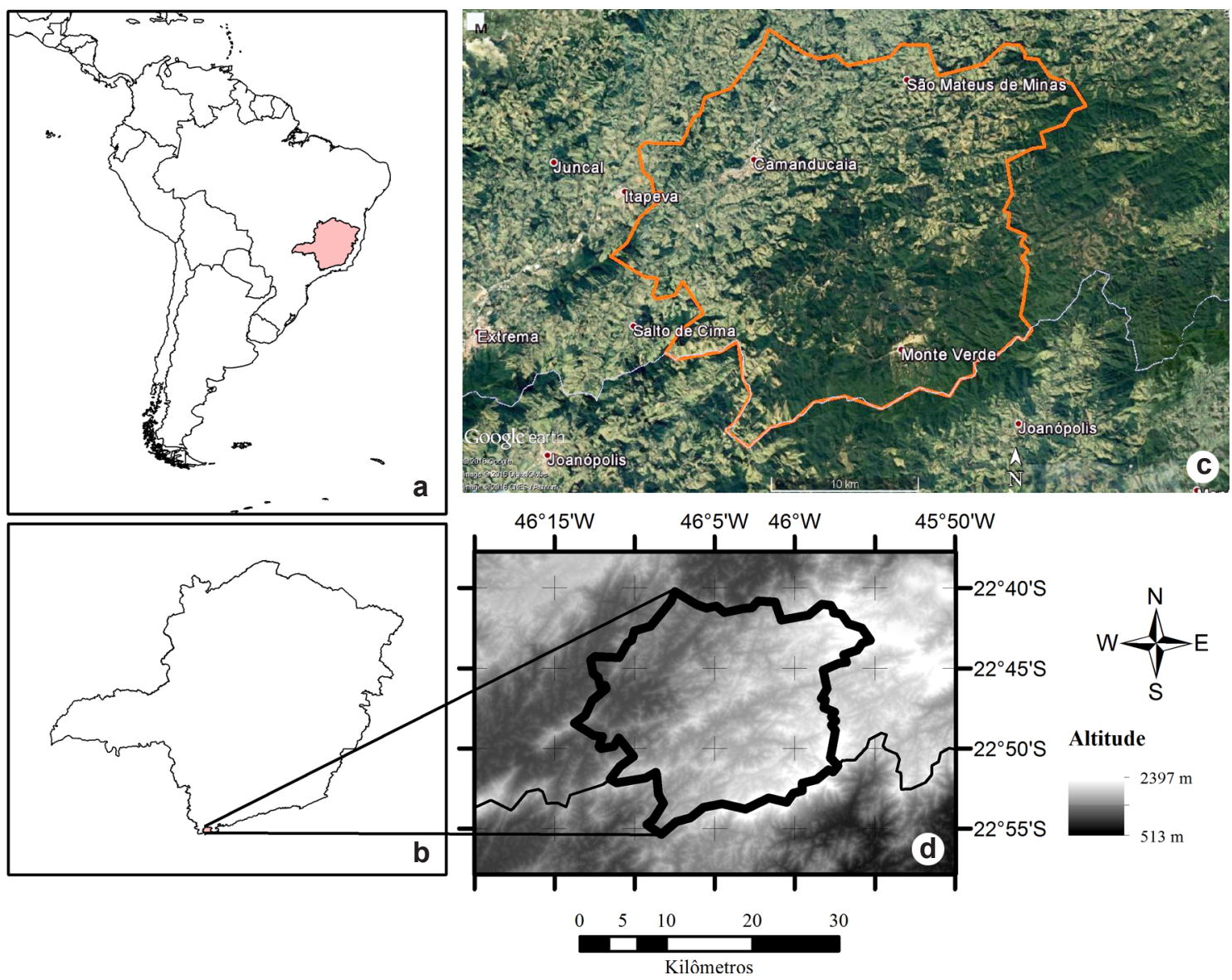

Figura 1 - a-b. localização geográfica do município de Camanducaia, Minas Gerais; c. imagem de satélite da área do município (fonte: Google Earth); d. relevo.

Figure 1 - a-b. geographical location of Camanducaia municipality, Minas Gerais; c. satellite image of the municipality area (source: Google Earth); d. relief.

limites do município compreendem um mosaico de áreas urbanas, monoculturas de eucalipto, pastagens e cobertura de vegetação nativa (Fig. 1c). As fitofisionomias nativas encontradas na região são floresta ombrófila densa alto-montana, floresta ombrófila mista montana (mata de araucária), campos de altitudes e afloramentos rochosos (Meireles et al. 2014). A altitude varia de ca. de 1.100 a 2.100 m (França \& Stehmann 2004; Fig. 1d). O clima é caracterizado como Cfb segundo a classificação de Köppen (Alvares et al. 2013).

\section{Levantamento florístico}

Este estudo se baseou em viagens de coleta em Camanducaia, bem como no distrito de Monte Verde, e análise de coleções da família depositadas em herbários. Dez viagens de coleta foram realizadas: nos meses de abril (duas viagens), julho e setembro de 2012; janeiro, abril e dezembro de 2013; julho de 2014; e agosto e setembro de 2015, totalizando ca. de 160 espécimes coletados. Estas coletas ocorreram de maneira assistemática, principalmente em fragmentos ao longo da estrada que liga Camanducaia a Monte Verde, e nos arredores deste distrito, ao longo de suas trilhas e picos. Os espécimes foram identificados com base em literatura específica da família (Cabral 2009; Cabral et al. 2011; Costa 2004; Delprete et al. 2004; Delprete et al. 2005; Gomes 2003; Jung-Mendaçolli 2007; Macias 1988; Souza et al. 2010; Taylor 2015), consulta a imagens de materiais tipo disponíveis no "Global Plants on JSTOR" (ITHAKA, todos os direitos reservados; $<$ http://plants.jstor.org/>), comparação com as coleções depositadas nos herbários analisados e/ou consulta a especialistas na família. Uma pesquisa 
prévia foi feita utilizando o banco de dados do speciesLink (<http://www.splink.org.br/>) para um levantamento de coleções representativas a serem analisadas. Os herbários BHCB, ESA, HRCB, IAC, ICN, MBM, SP e UEC foram analisados. Sinonímias e atualizações nomenclaturais dos táxons inventariados seguem Taylor (2015) e Barbosa at al. (2015), sendo que apenas os sinônimos homotípicos foram citados. Dos materiais analisados, coleções representativas foram selecionadas para compor o item Material selecionado.

Lista de descritores para a elaboração da chave interativa

Uma lista de 33 descritores (Apêndice) foi elaborada para os táxons, sendo cinco descritores dependentes (aplicáveis somente em determinada seleção de estado do descritor ao qual está subordinado). Para estes descritores, são propostos 152 estados, obtidos através da análise dos espécimes provenientes de Camanducaia ou localidades próximas. Dados de estruturas ausentes (e.g., flor de Borreria ocymifolia (Willd.) Bacigalupo \& E.L.Cabral e Coccocypselum lanceolatum (Ruiz \& Pav.) Pers., e fruto e semente de Manettia pubescens Cham. \& Schltdl.) foram obtidos através de consulta a materiais adicionais e/ou literatura. A terminologia morfológica segue Radford et al. (1974) e literatura taxonômica específica da família (Cabral 2009; Cabral et al. 2011; Costa 2004; Delprete et al. 2004; Delprete et al. 2005; Gomes 2003; Jung-Mendaçolli 2007; Macias 1988; Souza et al. 2010; Taylor 2015).

Chave interativa: software utilizado A princípio, os dados foram inseridos no programa Xper ${ }^{2}$ version 2.2 (Ung et al. 2010), e posteriormente exportados em formato sdd para $\mathrm{Xper}^{3}$, que permite o armazenamento e edição de dados online. Os táxons, descritores e estados, foram inseridos na base de dados "Rubiaceae no município de Camanducaia, MG, Brasil". Fotografias retiradas em campo e ilustrações, quando disponíveis, foram inseridas para ilustrar estados dos descritores e táxons. O programa oferece ferramentas para a visualização e edição dos dados em forma de matriz, comparação entre táxons ou grupos de táxons, e análise da base através da ferramenta "checkbase", assegurando a consistência dos dados.

\section{Resultados}

Rubiaceae está representada no município de Camanducaia por 35 espécies, duas subespécies e duas variedades, classificadas em 17 gêneros. Borreria G.Mey., Manettia Mutis ex L. e Psychotria L. foram os gêneros mais diversos, apresentando cinco espécies cada, seguidos por Coccocypselum P.Browne, Galianthe Griseb. ex Lorentz, Galium L. e Palicourea Aubl., os quais apresentam três espécies cada. Onze táxons são endêmicos do domínio da Mata Atlântica (Cordiera concolor (Cham.) Kuntze var. concolor, Galianthe vaginata E.L. Cabral \& Bacigalupo, Manettia glaziovii Wernham, Manettia gracilis Cham. \& Schltdl., Palicourea jungiana C.M. Taylor, Palicourea rudgeoides (Müll.Arg.) Standl., Psychotria beyrichiana Müll. Arg., Psychotria niveobarbata (Müll. Arg.) Britton, Psychotria sp. (三Psychotria dusenii Standl. nom. illeg.), Psychotria suterella Müll. Arg., Rudgea jasminoides (Cham.) Müll. Arg. subsp. jasminoides), sendo dois deles ( $G$. vaginata e $P$. beyrichiana) endêmicos da Serra da Mantiqueira e Serra do Mar, no Sudeste do Brasil. Psychotria beyrichiana é registrada pela primeira vez no estado de Minas Gerais.

\section{Chave interativa}

A base de dados "Rubiaceae no município de Camanducaia, MG, Brasil" foi criada e armazenada online em $\mathrm{Xper}^{3}$, possibilitando a sua constante atualização a partir da inserção de novos táxons, descritores, estados e imagens, quando disponíveis. A chave interativa de entradas múltiplas (CIEM; Fig. 2) encontra-se disponível em (<http://xper3.com/xper3GeneratedFiles/ publish/identification/-6539033069138523847/ mkey.html> ou <http://www.xper3. $\mathrm{fr} / \mathrm{xp}$ er $3 \mathrm{GeneratedFiles/publis} \mathrm{h/}$ identification/-6539033069138523847/mkey. html $>$ ).

Na CIEM produzida, os descritores são apresentados em escala de verde, seguindo dos mais discriminantes (verde escuro) para os menos discriminantes (verde claro a branco). Ao selecionar os estados dos descritores desejados, os táxons nos quais estes não estão presentes são eliminados gradualmente, até que o processo de identificação seja concluído. Então, ao clicar no nome do táxon, uma janela é apresentada contendo imagens e uma descrição baseada nos estados de caráter inseridos na base de dados. 


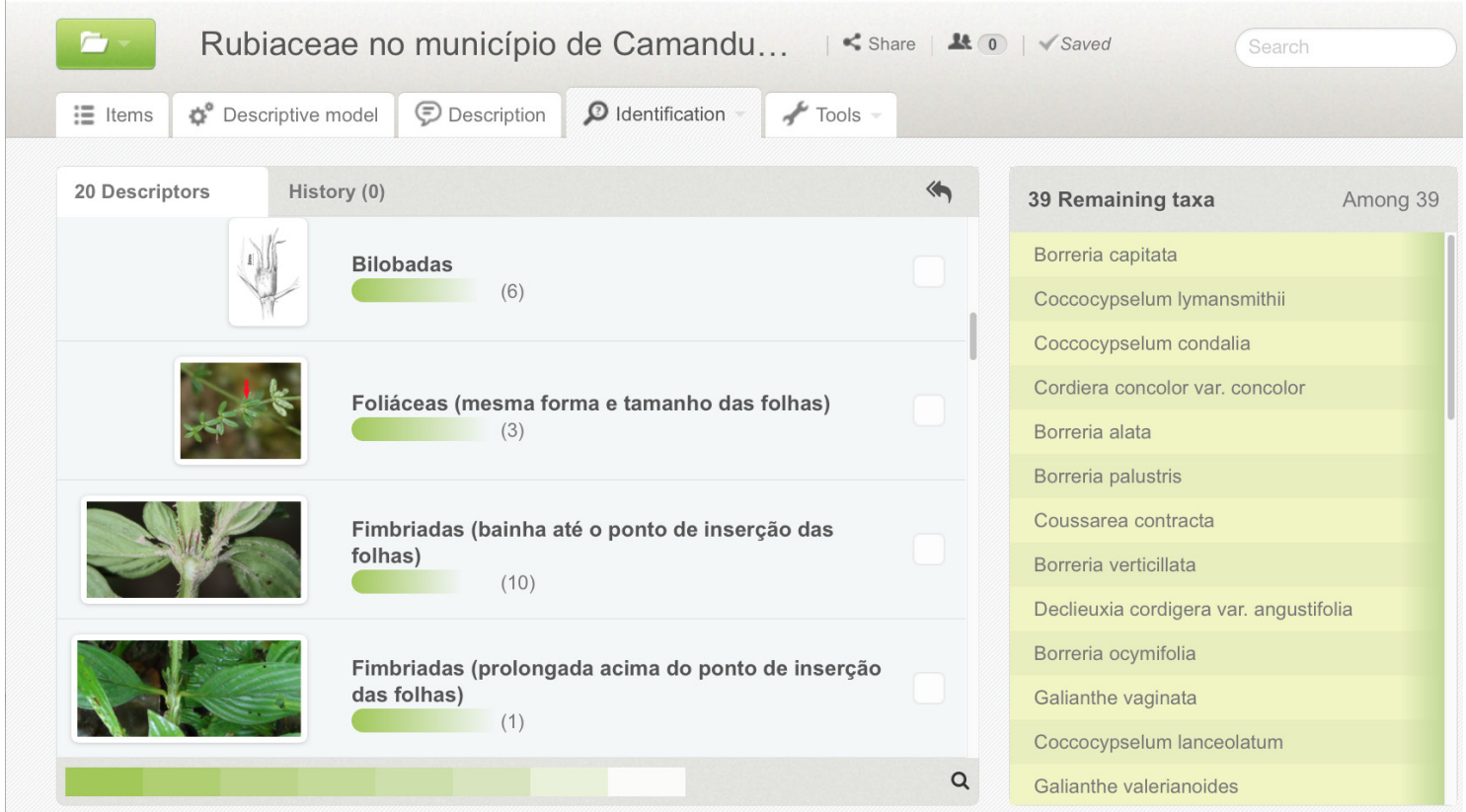

Figura 2 - Interface da chave interativa de entradas múltiplas para Rubiaceae no município de Camanducaia, Minas Gerais, Brasil, em Xper ${ }^{3}$. Os estados para o descritor "estípula", o qual foi previamente selecionado, são apresentados à esquerda, e a lista dos táxons, os quais serão eliminados gradualmente de acordo com a seleção dos estados, à direita.

Figure 2 - Interactive Key for the Rubiaceae in Camanducaia municipality, Minas Gerais, Brazil interface in Xper ${ }^{3}$. States for the "estípula" descriptor, which was previously selected, are presented to the left, and the list of taxa, which are gradually eliminated according to the selection of states, to the right.

\section{Sinópse de Rubiaceae para Camanducaia, MG}

1. Borreria alata (Aubl.) DC., Prodr. 4: 544 (1830) Spermacoce alata Aubl., Hist. Pl. Guiane: 60 (1775).

Borreria alata ocorre no México, Antilhas e América do Sul (Burger \& Taylor 1993). No Brasil, habita quase todo o país, podendo ocorrer área antrópica, caatinga (stricto sensu), campinarana, campo limpo, campo rupestre, cerrado (lato sensu), floresta ombrófila e restinga (BFG 2015). Em Camanducaia foi coletada em trilhas, margem de estradas e subosque de floresta ombrófila, com flores e frutos de dezembro a janeiro. Caracterizase pelo hábito herbáceo decumbente, estípulas fimbriadas, inflorescências em glomérulos 2-bracteados, paucifloros (até 7 flores) e flores com estigma bilobado. Ilustração em Burger \& Taylor (1993) sob Spermacoce latifolia Aubl.

Material selecionado: Monte Verde, trilha para Pedra Partida, 18.XII.2013, fl. e fr., J.A.M. Carmo et al. 143 (UEC).
2. Borreria capitata (Ruiz \& Pav.) DC., Prodr. 4: 545 (1830)

三Spermacoce capitata Ruiz \& Pav., Fl. Peruv. 1: 61 (1798).

Fig. 3a,b

Borreria capitata distribui-se pela América do Sul na Guiana Francesa, Venezuela, Peru e Bolívia, e em quase todos os estados do Brasil, em área antrópica, caatinga (stricto sensu), campo de altitude, campo limpo, campo rupestre, carrasco, cerrado (lato sensu), restinga e afloramentos rochosos (BFG 2015). Em Camanducaia foi coletada em margem de estradas e pastos, com flores e frutos em abril. Esta espécie apresenta variação na largura da lâmina foliar, entretanto, pode ser caracterizada pelo hábito herbáceo a subarbustivo, ereto, ramos pubescentes, principalmente nos ângulos, estípulas fimbriadas, inflorescências em glomérulos multifloros (mais de 10 flores), portando 4-6(-10) brácteas foliáceas.

Material selecionado: Estrada Camanducaia-Monte Verde, 27.IV.2013, fl. e fr., J.A.M. Carmo et al. 132 (UEC). 


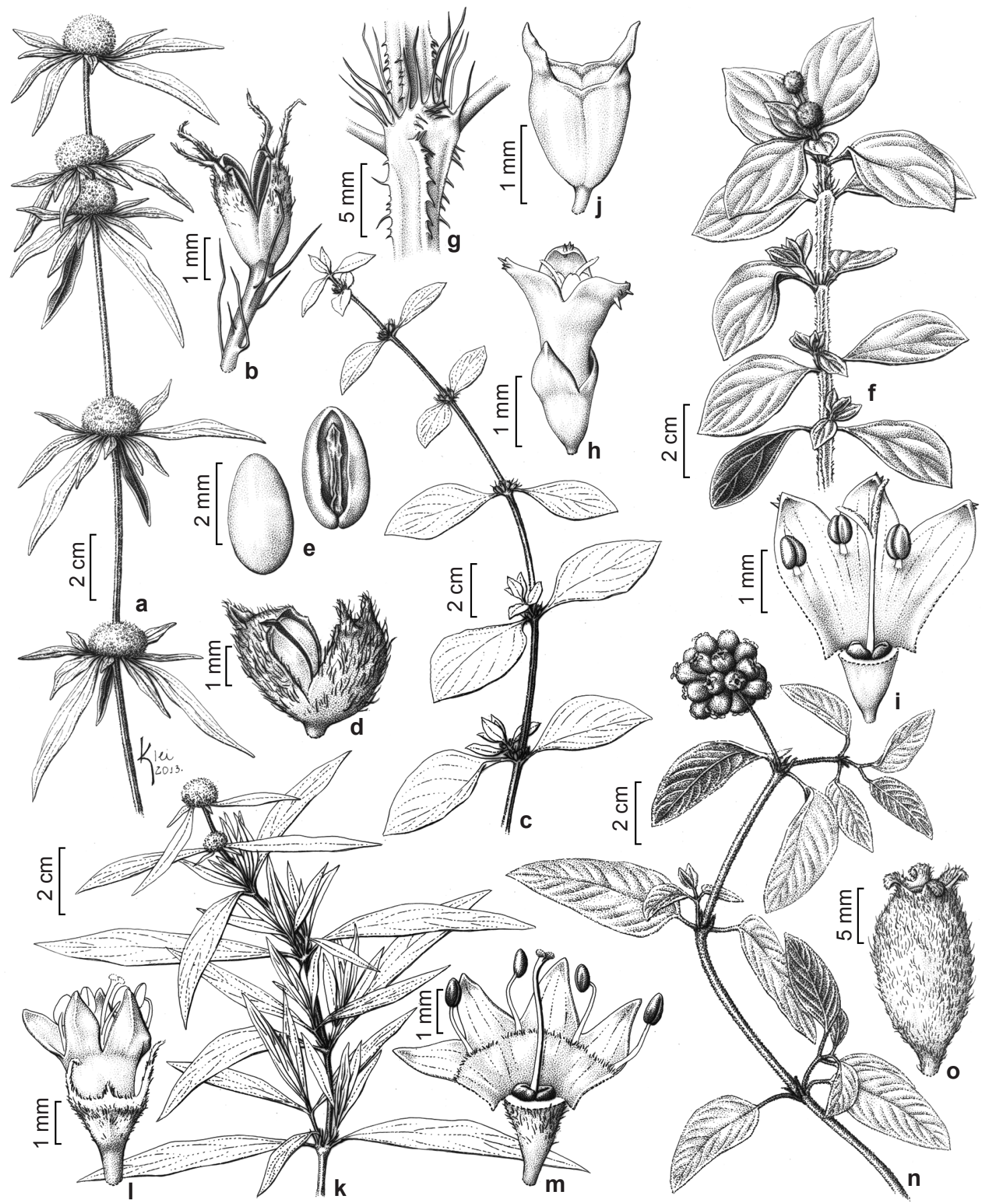

Figura 3 -a-b. Borreria capitata - a. ramo com inflorescências; b. fruto. c-e. B. ocymifolia - c. ramo com inflorescências; d. fruto; e. semente, vista dorsal (esquerda) e ventral (direita). f-j. B. palustris - f. ramo com inflorescência; g. estípula e detalhe do ramo alado no ápice do entrenó; h-i. flor; j. fruto. k-m. B. verticillata - k. ramo com inflorescências; 1-m. flor. n-o. Coccocypselum lanceolatum - n. ramo com inflorescência; o. fruto. (a-b: Carmo 29; c-e: Carmo 6; f-j: Carmo 125; k-m: Carmo 45; n-o: Carmo 130). Ilustração: Klei Sousa.

Figure 3 - a-b. Borreria capitata - a. branch with inflorescences; b. fruit. c-e. B. ocymifolia - c. branch with inflorescences; d. fruit; e.seed, dorsal (left) and ventral (right) views. f-j. B. palustris - f. branch with inflorescence; g. stipule and detail of the winged branche at the apex of the internode; h-i. flower; j. fruit. k-m. B. verticillata - k. branch with inflorescences; $1-\mathrm{m}$. flower; n-o. Coccocypselum lanceolatum - $\mathrm{n}$. branch with inflorescence; o. fruit. (a-b: Carmo 29; c-e: Carmo 6; f-j: Carmo 125; k-m: Carmo 45; n-o: Carmo 130). Illustration: Klei Sousa. 
3. Borreria ocymifolia (Willd.) Bacigalupo \& E.L. Cabral, Opera Bot. Belg. 7: 307 (1996)

三Spermacoce ocymifolia Willd., Syst. Veg., ed. 15 bis 3: 530 (1819).

Fig. 3c-e

Borreria ocymifolia distribui-se nas Antilhas, América Central e do Sul (Cabral et al. 2011). No Brasil ocorre em quase todos os estados, em área antrópica, caatinga (stricto sensu), campo de várzea, campo rupestre, cerrado (lato sensu), floresta ciliar ou galeria, floresta de terra firme, floresta estacional semidecidual e restinga (BFG 2015). Em Camanducaia foi coletada em margem de estradas e pastos. Encontrada com frutos em abril. Caracteriza-se pelo porte ereto, com escassas ramificações, estípulas fimbriadas, 7-9 glomérulos por ramo, brácteas cada vez menores em direção ao ápice do ramo e cápsula separandose em dois mericarpos indeiscentes, ou apenas um parcialmente deiscente.

Material selecionado: Estrada Camanducaia-Monte Verde, 3.VI.2013, fr., J.A.M. Carmo et al. 18 (UEC).

4. Borreria palustris (Cham. \& Schltdl.) Bacigalupo \& E.L. Cabral, Hickenia 2: 264 (1998)

$\equiv$ Diodia palustris Cham. \& Schltdl., Linnaea 3: 347 (1828).

Fig. $3 \mathrm{f}-\mathrm{j}$

Borreria palustris distribui-se no Sudeste e Sul do Brasil, Colômbia, Peru e nordeste da Argentina (Cabral et al. 2011). No Brasil ocorre da Bahia ao Rio Grande do Sul, floresta ciliar ou galeria, floresta estacional semidecidual, floresta ombrófila, floresta ombrófila mista e vegetação aquática (BFG 2015). Em Camanducaia foi coletada em campos brejosos e em bordas de fragmentos de mata, com flores e frutos de janeiro a abril. Caracteriza-se pelos ramos conspicuamente alados, asas de margem escabra a denteada, estípulas fimbriadas, inflorescências em tirso com inflorescências parciais glomeriformes, flores com corola 3-lobada e frutos dividindo-se em mericarpos indeiscentes e caducos.

Material selecionado: Estrada Camanducaia-Monte Verde, 27.VI.2013, fl. e fr., J.A.M. Carmo et al. 125 (UEC).

5. Borreria verticillata (L.) G. Mey., Prim. Fl. Esseq.: 83 (1818)

三Spermacoce verticillata L., Sp. Pl.: 102 (1753).

Fig. 3k-m

Segundo Cabral et al. (2011), Borreria verticillata distribui-se desde os EUA até o norte da Argentina, e é uma espécie introduzida no oeste da África. No Brasil ocorre em quase todos os estados, em área antrópica, caatinga (stricto sensu), campinarana, campo limpo, campo rupestre, carrasco, cerrado (lato sensu), floresta de terra firme, floresta estacional decidual, floresta estacional semidecidual, floresta ombrófila mista, restinga e afloramentos rochosos (BFG 2015). Em Camanducaia foi coletada em margem de estradas e trilhas e em afloramentos rochosos, com flores e frutos de junho a maio. Esta espécie apresenta variação quanto ao tamanho e forma das folhas, entretanto pode ser caracterizada pelas folhas pseudoverticiladas pela formação de braquiblastos, estípulas fimbriadas, ramos com 1-2 glomérulos terminais e flores com cálice 2-lobado.

Material selecionado: Monte Verde, trilha para a Pedra Partida, 18.XII.2013, fl. e fr., J.A.M. Carmo et al. 146 (UEC).

6. Coccocypselum condalia Pers., Syn. Pl. 1: 132 (1805).

Coccocypselum condalia ocorre nas Guianas, Venezuela, Colômbia, Equador, Peru, Paraguai e Brasil, nas regiões Sudeste e Sul, bem como no Mato Grosso e Mato Grosso do Sul, em floresta ombrófila densa e mista, bordas de mata e campos, em locais úmidos, geralmente sombreados (Costa 2004). Em Camanducaia foi coletada em bordas de mata, floresta de galeria, floresta ombrófila densa e mista e em áreas de transição entre floresta ombrófila densa montana e afloramentos rochosos, com flores e frutos durante todo o ano. Esta espécie apresenta variação em relação à forma da lâmina foliar, principalmente na base, que pode ser oblíqua, truncada ou cordada, entretanto pode ser caracterizada pelo hábito reptante, inflorescências em cimeiras fasciculadas congestas, subglobosas, e flores com lobos do cálice desiguais, com a face adaxial glabra. Ilustração em Costa (2004).

Material selecionado: Monte Verde, trilha para a Pedra Partida, 18.XII.2013, fl., J.A.M. Carmo et al. 138 (UEC); trilha para o Platô, $1.836 \mathrm{~m}, 22^{\circ} 52^{\prime} 47^{\prime \prime} \mathrm{S}, 46^{\circ} 1^{\prime} 58^{\prime \prime} \mathrm{W}$, 12.VII.2012, fr., J.A.M. Carmo et al. 44 (UEC).

7. Coccocypselum lanceolatum (Ruiz \& Pav.) Pers., Syn. Pl. 1: 132 (1805)

三 Condalia lanceolata Ruiz \& Pav., Fl. Peruv. 1: 54 (1798).

Fig. 3n,o

Coccocypselum lanceolatum possui ampla distribuição nos Neotrópicos, desde o sul do México até a Argentina, ocorrendo em floresta ombrófila densa, floresta de galeria, cerradões, campos e subosque de eucaliptos (Costa 2004). Em Camanducaia foi coletada em margem de 
estrada, com flores e frutos em abril. Esta espécie pode ser caracterizada pelo hábito reptante, indumento velutino, ocasionalmente apresentando tricomas arroxeados, inflorescência em cimeiras congestas, globosas, e flores com lobos do cálice reflexos, velutinos em ambas as faces.

Material selecionado: Estrada Camanducaia-Monte Verde, 27.VI.2013, fr., J.A.M. Carmo 129 (UEC).

8. Coccocypselum lymansmithii Standl., Publ. Field Mus. Nat. Hist., Bot. Ser. 8: 165 (1930).

Coccocypselum lymansmithii típica dos campos de altitude do Sudeste e Sul do Brasil, ocorrendo também no Distrito Federal, chegando até o Paraguai (Costa 2004). Em Camanducaia foi coletada crescendo sobre rochas às margens de córregos, em floresta ombrófila mista e floresta ombrófila densa alto-montana, com flores em junho e frutos em março. Caracteriza-se pelo hábito reptante, pela forma oval a orbicular da lâmina foliar, que apresenta tamanho relativamente reduzido $(5,7-$ 9,9 × 5,3-10,6 mm), e inflorescências unifloras. Ilustração em Costa (2004).

Material selecionado: Monte Verde, trilha para a Pedra do Selado, 22 53'19"S, 46²'00"W, 22.VIII.2015, fl. e fr., J.A.M. Carmo et al. 403 (UEC).

9. Cordiera concolor (Cham.) Kuntze var. concolor, Revis. Gen. Pl. 1: 279 (1891). Fig. 4a

Cordiera concolor var. concolor ocorre em Minas Gerais e Rio de Janeiro até Santa Catarina, Paraguai e nordeste da Argentina, em formações do domínio da Mata Atlântica (Delprete et al. 2004). Em Camanducaia foi coletada em subosque de floresta ombrófila densa montana, com flores em janeiro e frutos de fevereiro a junho. Caracteriza-se pelos indivíduos dióicos, estípulas triangulares a subuladas unidas ao redor do caule formando uma curta bainha, inflorescências masculinas fasciculadas e femininas unifloras, flores com cálice truncado e fruto 3-5-seminado.

Material selecionado: Mata do Romulo, $1.563 \mathrm{~m}$, 6.VI.2000, fr., R.B. Torres 1236 (IAC, UEC).

Material adicional selecionado: BRASIL. MINAS GERAIS: Poços de Caldas, Campo de Santa Rosalia, 21'50'20"'S, 46³3'53"W, 13.I.1981, fl., L.S.K. Gouvea 785 (UEC).

10. Coussarea contracta (Walp.) Müll. Arg., Flora 58: 467 (1875)

三Faramea contracta Walp., Nov. Actorum Acad. Caes. Leop.-Carol. Nat. Cur. 19(Suppl. 1): 331 (1843).

Coussarea contracta distribui-se na Argentina, Paraguai e Brasil nos estados da Bahia, Ceará,
Pernambuco, Goiás, Mato Grosso do Sul, Minas Gerais, Rio de Janeiro, São Paulo, Paraná, Santa Catarina e Rio Grande do Sul, em formações da Mata Atlântica, Cerrado e Pantanal (Gomes 2003). Em Camanducaia foi coletada em floresta ombrófila densa, com flores em novembro e frutos em janeiro. Caracteriza-se pelas estípulas curtamente unidas ao redor do caule, inflorescência em tirso, flores com cálice truncado a denticulado e drupas portando apenas um pirênio. Ilustração em Gomes (2003).

Material selecionado: Montes-Verdes, 19.XI.1979, fl., H.F. Leitão-Filho 10681 (SP, UEC).

Material adicional selecionado: BRASIL. MINAS GERAIS: Poços de Caldas, Fonte dos Amores, 12.I.1981, fr., L.A.F. Mathes 664 (UEC).

11. Declieuxia cordigera var. angustifolia Müll. Arg., Fl. bras. 6(5): 434 (1881).

Declieuxia cordigera var. angustifolia distribuise nos estados de Minas Gerais, São Paulo e Paraná, ocorrendo em campos e cerrados (BFG 2015). Em Camanducaia foi coletada sobre barranco em área impactada, com flores e frutos em outubro. Caracteriza-se por apresentar folhas ocasionalmente verticiladas, estípulas lineares, inflorescências em cimeiras compostas, com inflorescências parciais monocasiais ou dicasiais, e frutos esquizocárpicos, comprimidos lateralmente. Ilustração em Müller (1881) sob Declieuxia polygaloides var. aristolochia Müll.Arg.

Material selecionado: Monte Verde, 31.X.2001, fl. e fr., L.D. Meireles 703 (UEC).

12. Galianthe andersonii E.L. Cabral, Bonplandia 10: 119 (2000). Fig. 4b-d

Galianthe andersonii é endêmica de Minas Gerais, ocorrendo em afloramentos rochosos ou campos rupestres (Cabral 2009). Em Camanducaia foi coletada em afloramentos rochosos, com frutos em julho. Caracteriza-se por ser um subarbusto cespitoso de ramos fistulosos, e pelas estípulas fimbriadas, inflorescências em tirsos terminais e sementes comprimidas dorsiventralmente.

Material selecionado: Monte Verde, Platô, 12.VII.2012, fr., J.A.M. Carmo 50 (UEC).

13. Galianthe vaginata E.L. Cabral \& Bacigalupo, Ann. Missouri Bot. Gard. 84: 875 (1997).

Fig. 4e-1

Galianthe vaginata é endêmica do Sudeste do Brasil, nos estados de Minas Gerais, São Paulo e Rio de Janeiro, ocorrendo em campos de altitude, afloramentos rochosos e trilhas em floresta montana, na Serra da Mantiqueira e Serra 


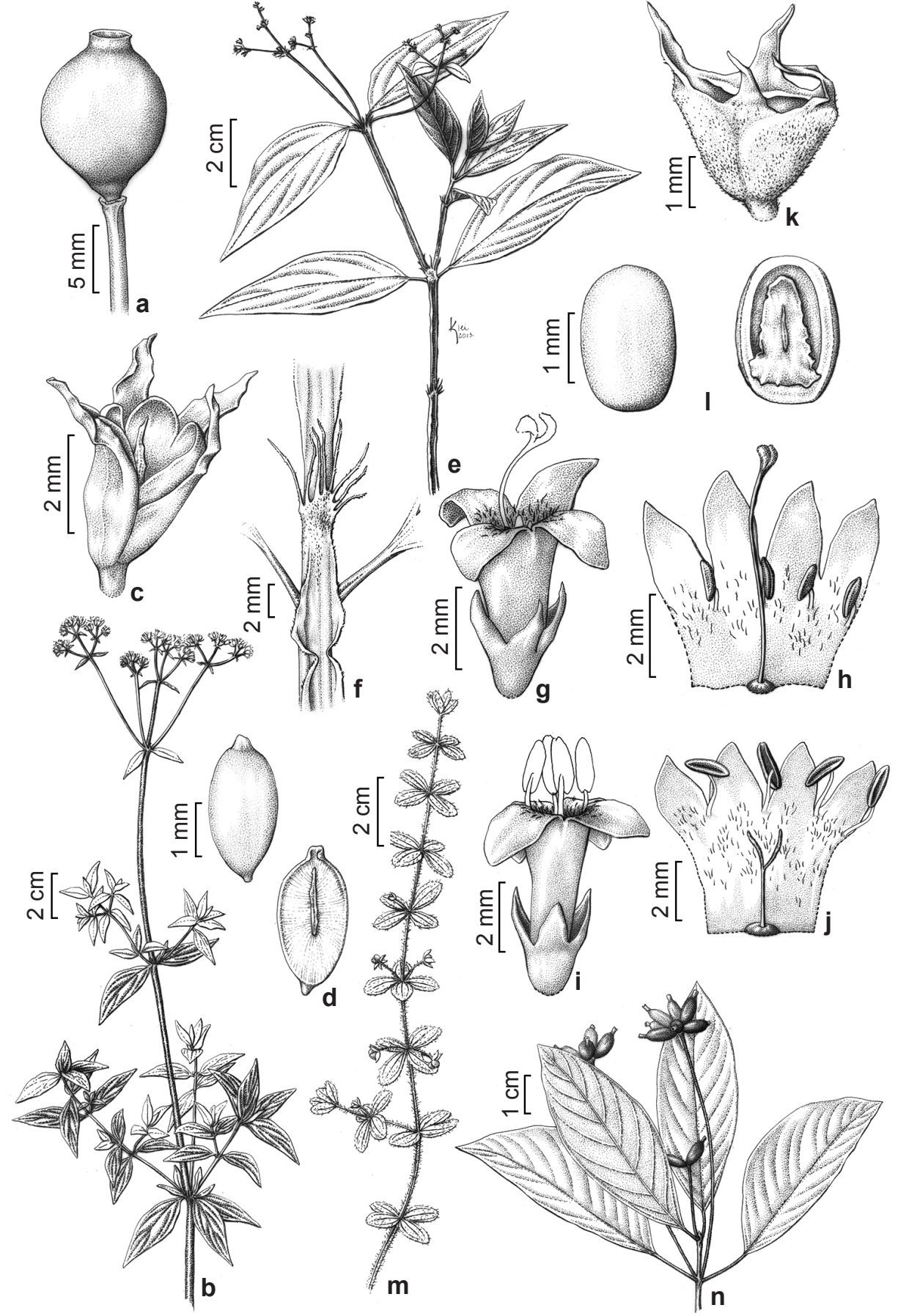

Figura 4 - a. Cordiera concolor var. concolor - fruto. b-d. Galianthe andersonii - b. ramo com inflorescências; c. fruto; d. semente, vista dorsal (esquerda) e ventral (direita). e-1. G. vaginata - e. ramo com inflorescências; f. estípula; g,h. flor longistila; i,j. flor brevistila; k. fruto; 1 . semente, vista dorsal (esquerda) e ventral (direita). m. Galium noxium - ramo com inflorescências. n. Guettarda uruguensis - ramo com inflorescências. (a. Torres 1236; b-d. Carmo 50; e,f,k,1. Carmo 24; g,h. Carmo 141; i,j. Carmo 142; m. Carmo 42; n. Torres 1473). Ilustração: Klei Sousa.

Figure 4-a. Cordiera concolor var. concolor - fruit. b-d. Galianthe andersonii-b. branch with inflorescences; c. fruit; d. seed, dorsal (left) and ventral (right) views. e-1. G. vaginata - e. branch with inflorescences; f. stipule; g,h. long-styled flower; i,j. short-styled flower; k. fruit; 1 . seed, dorsal (left) and ventral (right) views. m. Galium noxium - branch with inflorescences. n. Guettarda uruguensis - branch with inflorescences. (a. Torres 1236; b-d. Carmo 50; e,f,k,1. Carmo 24; g,h. Carmo 141; i,j. Carmo 142; m. Carmo 42; n. Torres 1473). Illustration: Klei Sousa. 
do Mar, sendo considerada "em perigo" em sua avaliação mais recente de status de conservação (Carmo et al. 2016). Em Camanducaia foi coletada em afloramentos rochosos e trilhas em floresta ombrófila densa alto-montana, com flores de setembro a janeiro e frutos em abril. Caracteriza-se pelos ramos conspicuamente alados, estípulas fimbriadas, bainha estipular desenvolvida até acima do ponto de inserção do par de folhas correspondentes e inflorescências em cimeiras compostas, com inflorescências parciais monocasiais ou dicasiais.

Material selecionado: Monte Verde, Trilha para a Pedra do Selado, 12.VI.2012, fr., J.A.M. Carmo et al. 24 (UEC); trilha para o Platô, 24.I.2013, fl., J.A.M. Carmo et al. 105 (UEC).

14. Galianthe valerianoides (Cham. \& Schltdl.) E.L. Cabral, Bol. Soc. Argent. Bot. 27: 246 (1991 publ. 1992)

$\equiv$ Borreria valerianoides Cham. \& Schltdl., Linnaea 3: 335 (1828).

Galianthe valerianoides distribui-se no nordeste da Argentina, leste do Paraguai e Brasil, no Distrito Federal, Goiás, Mato Grosso, Minas Gerais, Paraná, Rio Grande do Sul, Santa Catarina e São Paulo, ocorrendo em pântanos, baixios, estuários, banhados e próximo a córregos (Cabral 2009). Em Camanducaia foi coletada em áreas pantanosas e sobre afloramentos rochosos, com flores e frutos em dezembro. Caracteriza-se por ser um subarbusto cespitoso de ramos fistulosos, e pelas estípulas fimbriadas, inflorescências em tirsos terminais e laterais e sementes comprimidas dorsiventralmente. Ilustração em Cabral (2009). Material selecionado: Monte Verde, Platô, 12.XII.2001, fl. e fr., L.D. Meirelles \& R. Belinello 803 (UEC).

15. Galium hypocarpium (L.) Griseb., Fl. Brit. W. I.: 351 (1861)

$\equiv$ Valantia hypocarpia L., Syst. Nat. ed. 10, 2: 1307 (1759).

Galium hypocarpium possui distribuição geográfica ampla, desde as ilhas do Caribe, América Central e toda a América do Sul, ocorrendo no Brasil desde Minas Gerais até o Rio Grande do Sul, ao longo de bordas de floresta e margens de rio (Delprete et al. 2004). Em Camanducaia foi coletada em margem de estrada, borda e subosque de mata, florestas de galeria e pântanos, com flores e frutos em dezembro e janeiro. Espécie altamente variável em relação ao indumento e na forma e tamanho da lâmina foliar. Em Camanducaia pode ser identificada pelo porte herbáceo, prostrado ou escandente, estípulas foliáceas e 1-2 sementes por fruto, cuja coloração varia de laranja a vermelho. Ilustração em Schumann (1888) sob Relbunium hypocarpium (L.) Hemsl.

Material selecionado: Monte Verde, Platô, 12.VII.2012, fl. e fr., J.A.M. Carmo et al. 47 (UEC).

16. Galium nigroramosum (Ehrend.) Dempster, Allertonia 5: 300 (1990)

$\equiv$ Relbunium nigroramosum Ehrend., Bot. Jahrb. Syst. 76: 529 (1955).

Galium nigroramosum se distribui no Brasil, no sudoeste de Minas Gerais e desde o Rio de Janeiro ao Rio Grande do Sul, na Bolívia, Paraguai, Argentina e Uruguai (Delprete et al. 2004). Em Camanducaia foi coletada em borda de mata e estradas, com flores e frutos em dezembro e janeiro. Caracteriza-se pelo hábito herbáceo, ereto, tornando-se prostrada ao longo do desenvolvimento, ramos estrigulosos, estípulas foliáceas, folhas lanceoladas e duas sementes por fruto, cuja coloração varia de laranja a vermelho. Ilustração em Delprete et al. (2004).

Material selecionado: Estrada para Gonçalves, 20.XII.2013, fl. e fr., J.A.M. Carmo et al. 159 (UEC).

17. Galium noxium (A. St.-Hil.) Dempster, Allertonia 5: 292 (1990)

$\equiv$ Rubia noxia A. St.-Hil., Hist. Pl. Remarq. Brésil: 229 (1824).

Fig. $4 \mathrm{~m}$

Galium noxium distribui-se no Peru, Bolívia, Paraguai, Argentina, Uruguai e no Brasil, em Goiás e da Bahia até o Rio Grande do Sul, sendo encontrada em solos úmidos, brejos e lugares sombrios, em campos, bosques e florestas de galeria (Delprete et al. 2004). Em Camanducaia foi coletada em margem de estradas e trilhas, com flores e frutos de abril a julho. Caracteriza-se pelo hábito herbáceo, prostrado, estípulas foliáceas, folhas trinérveas e frutos brancos.

Material selecionado: Estrada Camanducaia-Monte Verde, 3.VI.2012, fr., J.A.M. Carmo et al. 15 (UEC).

Material adicional selecionado: BRASIL. SÃO PAULO: Campos do Jordão, Pico do Itapeva, Parque Estadual de Campos do Jordão, 9.VI.2000, fl., L.O. Anderson 00/35 (UEC).

18. Guettarda uruguensis Cham. \& Schltdl., Linnaea 4: 183 (1829).

Fig. 4n

Guettarda uruguensis distribui-se no Brasil, nos estados da Bahia, Minas Gerais, Rio de Janeiro, São Paulo, Paraná, Santa Catarina e Rio Grande do Sul e Uruguai, em floresta de galeria ou estacional (Barbosa 2007). Em Camanducaia foi coletada em 
floresta de galeria, com flores em outubro e frutos em dezembro. Caracteriza-se pelas inflorescências axilares em cimeiras, flores com cálice tubuloso, truncado a (2-)3-lobado, corola salverforme de prefloração imbricada e estigma capitado.

Material selecionado: Mata Ciliar do Rio Camanducaia, 1.039 m, 10.X.2000, fl., R.B. Torres 1346 (IAC); Mata da Patrícia, 1.116 m, 11.XII.2001, fr., R.B. Torres 1473 (IAC, UEC).

19. Manettia congesta (Vell.) K. Schum., Fl. bras. 6(6): 177 (1889)

三 Guagnebina congesta Vell., F1. Flumin. 1: t. 119 (1829).

Manettia congesta é endêmica do estado de Minas Gerais, ocorrendo em floresta estacional semidecidual (BFG 2015). Em Camanducaia foi coletada em trilha em floresta ombrófila densa montana, com flores e frutos em abril. Caracterizase pelo hábito lianescente, indumento esparsamente pubescente nos ramos e lâmina foliar membranácea de face adaxial glabra, face abaxial glabra a esparsamente pubescente ao longo das nervuras primária e secundárias, lobos do cálice glabros e corola braca. Ilustração em Macias (1998).

Material selecionado: Monte Verde, Trilha para o Platô, 1.VII.2014, fl. e fr., J.A.M. Carmo et al. 195 (UEC).

\section{Manettia glaziovii Wernham, J. Bot. 57(Suppl.):} 36 (1919).

Fig. 5a-d

Manettia glaziovii distribui-se nos estados de Minas Gerais, Rio de Janeiro, São Paulo, Paraná, ocorrendo em floresta ombrófila (BFG 2015). Em Camanducaia foi coletada em borda de floresta ombrófila densa montana, com flores e frutos em junho. Caracteriza-se pelo hábito lianescente, indumento velutino nos ramos e lâmina foliar, a qual apresenta consistência coriácea, lobos do cálice velutinos e corola braca.

Material selecionado: Estrada para Gonçalves, Pinheirão, 1.700 m, 20.VI.2000, fl., L.H.Y. Kamino 46 (SP); Monte Verde, trilha para o Platô, 12.VII.2012, fr., J.A.M. Carmo et al. 56 (UEC).

21. Manettia gracilis Cham. \& Schltdl., Linnaea 4: 169 (1829).

Manettia gracilis distribui-se no Brasil, de Minas Gerais ao Rio Grande do Sul, ocorrendo em floresta estacional semidecidual e floresta ombrófila (BFG 2015). Em Camanducaia foi coletada em subosque de mata, com flores em março e frutos em junho. Caracteriza-se pelo hábito lianescente, ramos, lâmina foliar, pedicelo e hipanto quase totalmente glabros, flores com corola vermelha, externamente esparsamente pubérula a glabra, com lobos estreitamente triangulares. Ilustração em Macias (1998).

Material selecionado: Mata do Chico Rei, 1.395 m, 20.III.2001, fl., R.B. Torres 1416 (IAC, UEC).

Material adicional selcionado: BRASIL. SÃO PAULO: Santo Antônio do Pinhal, 11.VI.1992, fr., A. Sartori 26578 (UEC).

22. Manettia luteorubra (Vell.) Benth., Linnaea 23: 445 (1850)

三 Guagnebina luteorubra Vell., F1. Flumin.: 46 (1829).

Manettia luteorubra distrubui-se no Distrito Federal, no Centro-oeste e Sudeste, ocorrendo em cerrado (lato sensu), floresta estacional semidecidual e floresta ombrófila (BFG 2015). Em Camanducaia foi coletada em margem de estradas, com flores e frutos em abril. Caracterizase pelo hábito lianescente, indumento tomentoso nos ramos, folhas e hipanto e flores com corola tubulosa, completamente vermelha ou tubo vermelho e lobos amarelos. Ilustração em Macias (1998).

Material selecionado: Estrada Camanducaia-Monte Verde, 3.VI.2012, fl. e fr., J.A.M. Carmo et al. 1 (UEC).

23. Manettia pubescens Cham. \& Schltdl., Linnaea 4: 170 (1829).

Manettia pubescens é endêmica do Brasil, de Minas Gerais ao Rio Grande do Sul, ocorrendo em cerrado (lato sensu), floresta estacional semidecidual, floresta ombrófila (BFG 2015). Em Camanducaia foi coletada em borda de mata, com flores e frutos em dezembro e abril. Manettia pubescens pode ser reconhecida pelo hábito lianescente, inflorescências em dicásio, ocasionalmente reduzidos a inflorescências unifloras, flores com corola relativamente longa (4-5 cm), vermelha, esparsamente tomentosa externamente, portando tricomas róseos. Ilustração em Macias (1998).

Material selecionado: Estrada Camanducaia-Monte Verde, 27.VI.2013, fl., J.A.M. Carmo et al. 133 (UEC).

\section{Margaritopsis sp.}

O espécime coletado encontra-se desprovido de estruturas reprodutivas. Considerando-se a importância da análise da inflorescência e flor para a identificação das espécies de Margaritopsis no Sudeste do Brasil (Taylor 2005), este espécime permanece indeterminado até a realização de novas coletas de materiais em estágio reprodutivo. Caracteriza-se por apresentar ramos achatados, 


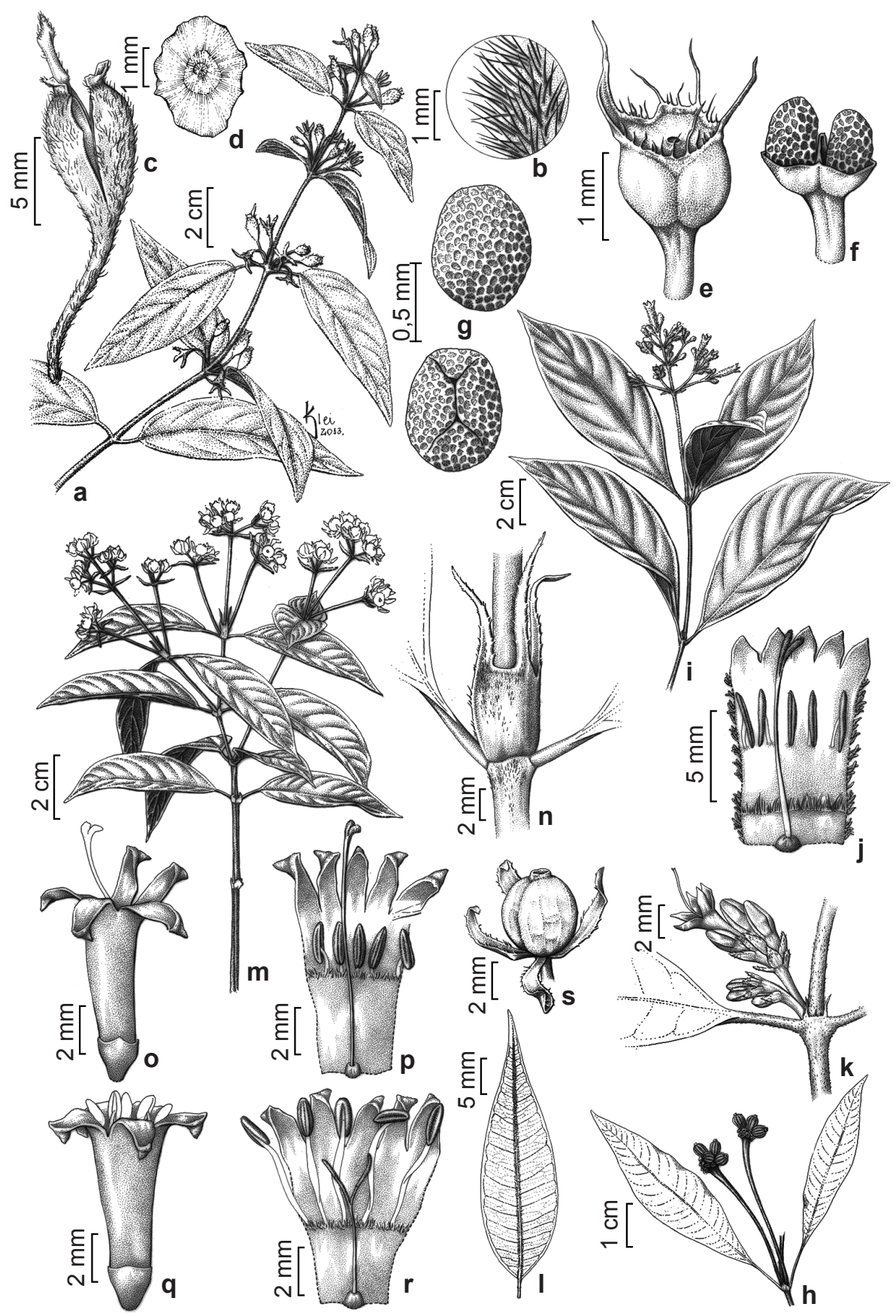

Figura 5 - a-d. Manettia glaziovii - a. ramo com inflorescências; b. indumento dos ramos; c. fruto; d. semente. e-g. Mitracarpus brasiliensis - e. fruto fechado; f. fruto aberto, porção inferior com sementes; g. semente, vista dorsal (acima) e ventral (abaixo). h. Palicourea jungiana - ramo com inflorescência. i,j. P. rudgeoides - i. ramo com inflorescências; j. flor aberta. k,1. P. sessilis - k. ramo com inflorescências; 1 . folha. m-s. Psychotria beyrichiana - m. ramo com inflorescências; n. estípula; o,p. flor longistila; q,r. flor brevistila; s. fruto. (a-d. Carmo 56; e-g. Carmo 19; h. Carmo 14; i,j. Carmo 115; k,1. Torres 884; m,n,s. Carmo 124; o,p. Carmo 136; q,r. Carmo 137). Ilustração: Klei Sousa.

Figure 5 -a-d. Manettia glaziovii - a. branch with inflorescences; b. indumentum on the branches; c. fruit; d. seed. e-g. Mitracarpus brasiliensis - e. closed fruit; f.opened fruit, inferior portion with seeds; g. seed, dorsal (up) and ventral (down) views. h. Palicourea jungiana-branch with inflorescence. i,j. P. rudgeoides - i. branch with inflorescences; j. opened flower. k,1. P. sessilis - k. branch with inflorescences; 1. leaf. $\mathrm{m}-\mathrm{s}$. Psychotria beyrichiana - m. branch with inflorescences; n. stipule; o,p. long-styled flower; q,r. short-styled flower; s. fruit. (a-d. Carmo 56; e-g. Carmo 19; h. Carmo 14; i,j. Carmo 115; k,1. Torres 884; m,n,s. Carmo 124; o,p. Carmo 136; q,r. Carmo 137). Illustration: Klei Sousa. 
costados em ambos os lados e estípulas bilobadas. Material selecionado: Estrada para Gonçalves, 20.XII.2013, J.A.M. Carmo et al. 160 (UEC).

25. Mitracarpus brasiliensis M. Porto \& Waechter, Fl. Ilustr. Rio Grande do Sul 12: 91 (1977).

Fig. 5e-g

Mitracarpus brasiliensis distribui-se nas regiões Sudeste e Sul do Brasil e noroeste da Argentina (Misiones), em campos degradados e margem de caminhos (Souza et al. 2010). Em Camanducaia foi coletada em margem de estrada, com flores e frutos em julho. Caracteriza-se pelas estípulas fimbriadas, fruto em cápsula circuncisa com a parte superior em forma de "mitra", e sementes com uma depressão ventral em " $X$ ".

Material selecionado: Melhoramentos, 13.VII.2012, fl. e fr., J.A.M. Carmo et al. 62 (UEC).

26. Palicourea jungiana C.M. Taylor, Novon 24 : 88 (2015).

Fig. $5 \mathrm{~h}$

Distribui-se no leste e Sudeste do Brasil, em floresta ombrófila (Taylor 2015). Em Camanducaia foi coletada em floresta ombrófila mista, floresta ombrófila densa montana e borda de mata, com flores em dezembro e frutos de fevereiro a agosto. Caracteriza-se por apresentar indivíduos arbóreos relativamente altos (5-15 m), estípulas bilobadas, inflorescências capitadas a espiciformes com pedúnculos relativamente longos $(1,3-2,7 \mathrm{~cm}$ compr.) e corola branca. O nome Palicourea jungiana substitui Psychotria longipes Müll. Arg., o qual está associado a Psychotria vellosiana Benth., cujas histórias taxonômicas são abordadas em detalhe por Taylor (2015).

Material selecionado: Estrada Camanducaia-Monte Verde, 3.VI.2012, fr., J.A.M. Carmo 14 (UEC).

Material adicional selecionado: BRASIL. MINAS GERAIS: Extrema, Serra do Lopo, 21.XII.2004, f1., L.F. Yamamoto 1791 (UEC).

27. Palicourea rudgeoides (Müll. Arg.) Standl., Publ. Field Mus. Nat. Hist., Bot. Ser. 8: 381 (1931) $\equiv$ Psychotria rudgeoides Müll. Arg., Fl. bras. 6(5): 463 (1881).

Fig. 5i,j

Palicourea rudgeoides distribui-se nos estados de Minas Gerais, São Paulo e Bahia, ocorrendo em floresta de galeria e floresta ombrófila (BFG 2015). Em Camanducaia foi coletada em subosque de floresta ombrófila mista, com flores de dezembro a janeiro e frutos de abril a julho. Caracteriza-se por apresentar folhas com filotaxia oposta, ocasionalmente verticilada, estípulas bilobadas, pedúnculo das inflorescências avermelhado, flores com corola amarela, com tricomas multicelulares de ápice avermelhado na face abaxial e coroa de tricomas rígidos abaixo da inserção dos estames.

Material selecionado: Estrada Camanducaia-Monte Verde, 24.VI.2013, fr., J.A.M. Carmo et al. 131 (UEC); Melhoramentos, 25.I.2013, fl., J.A.M. Carmo et al. 115 (UEC).

28. Palicourea sessilis (Vell.) C.M. Taylor, Novon 24: 90 (2015)

三Coffea sessilis Vell., Fl. Flumin.: 64 (1829).

Fig. $5 \mathrm{k}, 1$

Distribui-se em formações florestais da Mata Atlântica, do leste do Brasil ao centro do Paraguai, e do oeste da Guiana a sudeste da Venezuela (Taylor 2015). Em Camanducaia foi coletada em subosque de floresta ombrófila densa montana, com flores de outubro a novembro e frutos de janeiro a junho. Esta espécie pode ser caracterizada pelas estípulas bilobadas, folhas com lâmina lanceolada a estreitamente lanceolada e inflorescências fasciculadas, axilares, de pedúnculos relativamente curtos $(1,3-2,6 \mathrm{~mm})$. Os materiais de Palicourea sessilis depositados nos herbários visitados estão identificados como Psychotria vellosiana. A história nomenclatural desta espécie, bem como sua combinação no gênero Palicourea, são abordadas em detalhe por Taylor (2015).

Material selecionado: Mata dos Mota, 24.XI.1999, fl., R.B. Torres 958 (IAC, UEC); Melhoramentos, 24.I.2013, fr., J.A.M. Carmo et al. 118 (UEC).

29. Posoqueria latifolia (Rudge) Schult., Syst. Veg., ed. 15 bis 5: 227 (1819)

三Solena latifolia Rudge, Pl. Guian.: 26 (1805).

Espécie de ampla distribuição nos neotrópicos, ocorrendo desde o sul do México até o sul do Brasil (Macias 1988), ocorrendo em floresta de galeria, floresta de igapó, floresta de terra firme, floresta de várzea, floresta estacional perenifólia, floresta ombrófila densa e mista e restinga (BFG 2015). Em Camanducaia foi coletada em floresta de galeria, com frutos em outubro. Caracteriza-se pelo porte arbóreo, podendo chegar a $5 \mathrm{~m}$, estípulas triangulares, inflorescência corimbosa e flores de corolas hipocrateriformes relativamente longas (17-20 cm). Ilustração em Macias (1988). Material selecionado: fl., L.V. Costa (BHCB 41055). Material adicional selecionado: BRASIL. SÃO PAULO: São Miguel Arcanjo, Parque Estadual Carlos Botelho, 243'22"S, 47059'36”'W, 15.X.2004, fr., L.S. Kinoshita 300 (UEC). 
30. Psychotria beyrichiana Müll. Arg., Flora 59: 545 (1876).

Fig. 5m-s

Ocorre nos estados de São Paulo e Rio de Janeiro, em Mata Atlântica, em floresta de galeria e ombrófila (BFG 2015), sendo este o seu primeiro registro para o estado de Minas Gerais. Em Camanducaia foi coletada em subosque de floresta ombrófila densa montana, com flores de dezembro a janeiro e frutos em abril. Caracteriza-se pelas estípulas bilobadas unidas ao redor do caule formando uma bainha, inflorescência em cimeiras compostas, corimbiformes, inflorescências parciais monocasiais ou dicasiais congestas, brácteas lanceoladas ou oblanceoladas a liguladas.

Material selecionado: Estrada Camanducaia-Monte Verde, 27.VI.2013, fr., J.A.M. Carmo et al. 121 (UEC), fl., J.A.M. Carmo et al. 122 (UEC).

31. Psychotria niveobarbata (Müll. Arg.) Britton, Bull. Torrey Bot. Club 18: 110 (1891)

$\equiv$ Mapouria niveobarbata Müll. Arg., Fl. bras. 6(5): 401 (1881).

Fig. 6a

Distribui-se no Sudeste do Brasil, em capoeiras e brejos (BFG 2015) e na Bahia. Em Camanducaia foi coletada em subosque de mata de altitude, com flores em novembro e frutos em junho. Caracteriza-se pelos ramos internos com anel de pubescência densa formado por tricomas ferrugíneos, estípulas arredondadas a obtusas, e flores com corola relativamente pequena $(3-3,3$ mm compr.).

Material selecionado: Fazenda São José, $1.400 \mathrm{~m}$, 22045'18"S, 466' 16"'W, 20.VI.2000, fr., L.H.Y. Kamino 49 (BHCB, MBM); Mata dos Mota, 25.XI.1999, fl., R.B. Torres 972 (IAC, UEC).

\section{Psychotria sp.}

$\equiv$ Psychotria dusenii Standl., Publ. Field Mus. Nat.

Hist., Bot. Ser. 8: 378 (1931), nom. illeg.

Esta espécie foi descrita por Standley em 1931 como Psychotria dusenni. Estretanto, Schumann, em 1903, já havia descrito uma espécie africana com este nome, portanto $P$. dusenii sensu Standley é um nome ilegítimo. Até o momento, uma nova combinação para esta espécie ainda não foi publicada. Ocorre em Minas Gerais, São Paulo, Paraná e Santa Catarina, em floresta ombrófila e restinga (BFG 2015). Em Camanducaia foi coletada em floresta ombrófila. Encontrada com frutos em junho. Caracteriza-se pelas estípulas curtamente bilobadas, inflorescências em cimeiras compostas, de inflorescências parciais monocasiais ou dicasiais, e cálice tubular a infundibuliforme relativamente longo $(8-11 \mathrm{~mm})$, com ápice irregularmente 3-lobado, sendo os lobos ovados a triangulares.

Material selecionado: Monte Verde, 30.VI.2001, fr., L.D. Meireles 414 (UEC).

33. Psychotria stachyoides Benth., Linnaea 23: 464 (1850).

Fig. $6 \mathrm{~b}-\mathrm{f}$

Ocorre no Sudeste e Sul do Brasil, em floresta ombrófila e campo rupestre (BFG 2015). Em Camanducaia foi coletada em floresta ombrófila densa montana, com flores de maio a dezembro e frutos em janeiro. Caracteriza-se pelo porte herbáceo a arbustivo, indumento frequentemente velutino a hirsuto, estípulas bilobadas e inflorescências tirsóides com inflorescências parciais em dicásios congestos.

Material selecionado: Monte Verde, trilha para o Platô, 19.XII.2013, fl., J.A.M. Carmo et al. 153 (UEC), fr., 19.XII.2013, J.A.M. Carmo et al. 154 (UEC).

34. Psychotria suterella Müll. Arg., Fl. bras. 6(5): 380 (1881).

Fig. $6 \mathrm{~g}$

Psychotria suterella distribui-se no Sul e Sudeste do Brasil, chegando até a Argentina (Delprete et al. 2005), em floresta de galeria, floresta estacional perenifólia, floresta estacional semidecidual, floresta ombrófila (BFG 2015). Em Camanducaia foi coletada em floresta ombrófila, com flores em maio e frutos de dezembro a março. Espécie facilmente reconhecida pelas estípulas curtamente bilobadas, folhas de lâmina com ápice geralmente caudado, inflorescências fasciculares sésseis, flores com cálice tubular de ápice (4-)5-lobado e com lobos estreitamente triangulares.

Material selecionado: Mata do Chico Rei, $1.395 \mathrm{~m}$, 14.III.2001, fr., R.B. Torres 1418 (IAC, UEC); Mata do Milton Tóta, 1.278 m, 11.XII.2001, R.B. Torres 1468 (IAC, UEC).

Material adicional selecionado: BRASIL. MINAS GERAIS: Extrema, Campo de altitude nos arredores da cidade, $1.410 \mathrm{~m}, 22^{\circ} 53^{\prime} 34^{\prime \prime} \mathrm{S}, 46^{\circ} 19^{\prime} 53^{\prime}$ 'W, 13.V.2004, fl., L.S. Kinoshita 04/102 (UEC).

35. Randia ferox (Cham. \& Schltdl.) DC., Prodr. 4: 387 (1830)

三 Gardenia ferox Cham. \& Schltdl., Linnaea 4: 198 (1829).

Fig 6h,i

Distribui-se no nordeste da Argentina, sul e sudeste do Brasil e Paraguai oriental, em floresta estacional semidecidual ou floresta ombrófila (Judkevich et al. 2015). Em Camanducaia foi coletada em floresta ombrófila, com flores em outubro e frutos de outubro a março. Caracteriza-se 

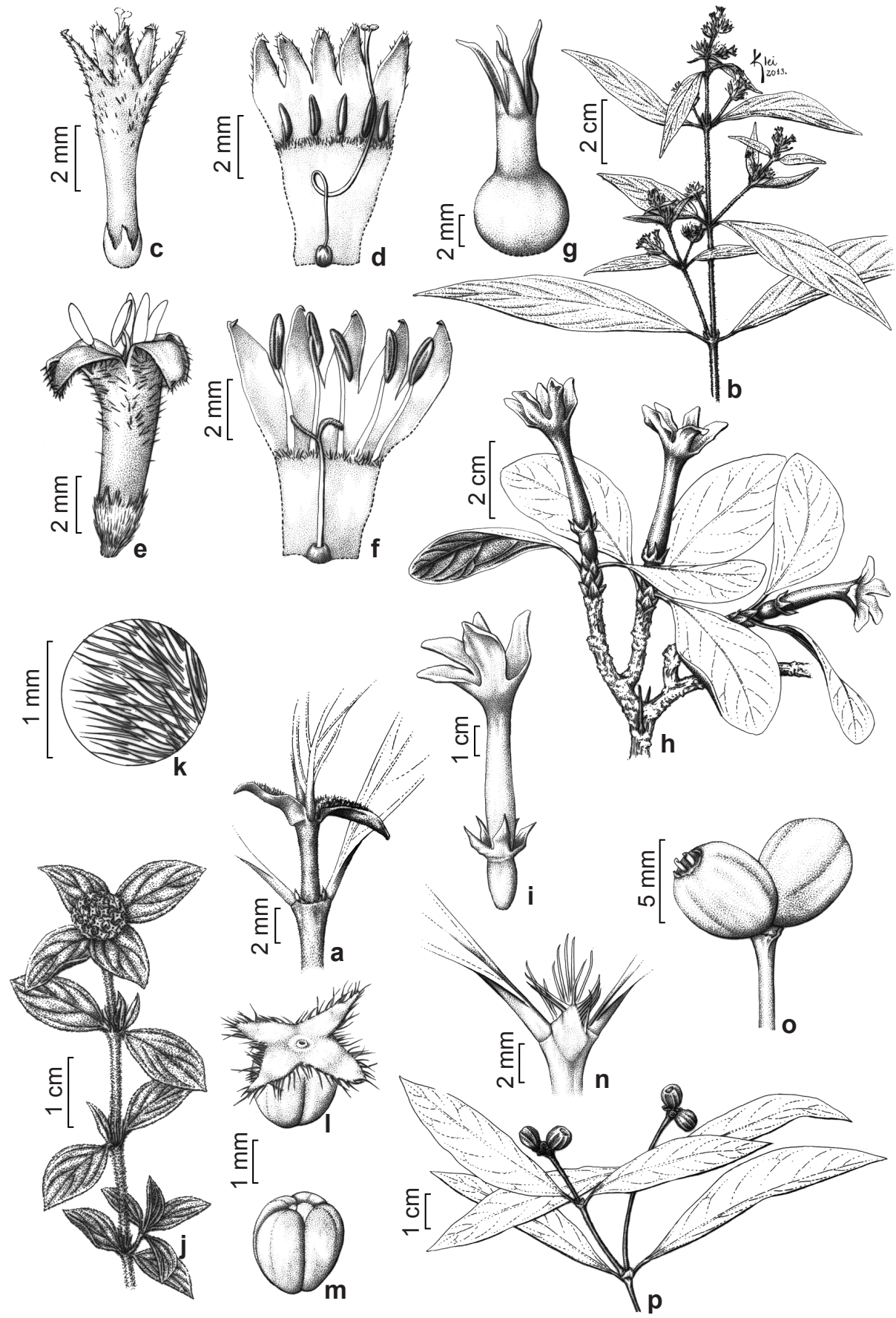

Figura 6 - a. Psychotria niveobarbata - estípula. b-f. P. stachyoides - b. ramo com inflorescências; c,d. flor longistila; e,f. flor brevistila. g. P. suterella - fruto; h,i. Randia armata - h. ramo com inflorescências femininas; i. flor feminina. $\mathrm{j}-\mathrm{m}$. Richardia humistrata - j. ramo com inflorescência; k. indumento do ramo; $1, \mathrm{~m}$. fruto. n,o. Rudgea jasminoides subsp. jasminoides - n. estípula; o. frutos. p. R. sessilis subsp. sessilis -ramo com inflorescências. (a. Torres 972; b-d: Torres 1032; e,f. Carmo 153; g. Torres 1468; h,i. Torres 854; j-m. Carmo 112; n,o. Carmo 68; p. Torres 1419). Ilustração: Klei Sousa. Figure 6 - a. Psychotria niveobarbata - stipule. b-f. P. stachyoides - b. branch with inflorescences; c,d. long-styled flower; e,f. short-styled flower. g. P. suterella - fruit; h,i. Randia armata - h. branch with feminine inflorescences; i. feminine flower. j-m. Richardia humistrata -j. branch with inflorescence; $\mathrm{k}$. indumentum on the branches; $1, \mathrm{~m}$. fruto. n,o. Rudgea jasminoides subsp. jasminoides $-\mathrm{n}$. stipule; o. fruits. p. R. sessilis subsp. sessilis: branch with inflorescences. (a. Torres 972; b-d: Torres 1032; e,f. Carmo 153; g. Torres 1468; h,i. Torres 854; j-m: Carmo 112; n,o. Carmo 68; p: Torres 1419). Illustration: Klei Sousa. 
por apresentar indivíduos dióicos, ramos armados e corola com prefloração contorta.

Material selecionado: Mata dos Mota, 14.X.1999, fl., R.B. Torres 854 (IAC, UEC).

Material adicional selecionado: BRASIL. SÃO PAULO: Valinhos, 955 m, 15.III.2009, fr., A.C.M. Costa 126(UEC).

36. Richardia brasiliensis Gomes, Mem. Ipecacuanha Bras.: 31 (1801)

$\equiv$ Richardsonia brasiliensis (Gomes) Klotzsch in F.G.Hayne, Getreue Darstell. Gew. 14: t. 21 (1846).

Richardia brasiliensis é uma espécie amplamente distribuída desde a América do Norte, Antilhas e toda a América do Sul e introduzida na África e Ásia (Delprete et al. 2005), ocorrendo em savanas, campos, dunas, locais impactados e como invasora de cultivos (Lewis \& Oliver 1974; Porto et al. 1977). Em Camanducaia foi coletada em margem de estradas, trilhas e pastos, com flores e frutos de janeiro a abril. Richardia brasiliensis apresenta grande variação em relação ao tamanho da lâmina foliar, mas pode ser facilmente caracterizada pelas estípulas fimbriadas, flores com cálice (5-)6-lobado, corola 6-lobada e fruto esquizocárpico, papilhosoestrigoso, separando-se em três mericarpos. Ilustração em Schumann (1888).

Material selecionado: Monte Verde, trilha para a Pedra do Selado, 12.VI.2012, fl. e fr., J.A.M. Carmo et al. 23 (UEC).

37. Richardia humistrata (Cham. \& Schltdl.) Steud., Nomencl. Bot., ed. 2, 1: 459 (1840)

$\equiv$ Richardsonia humistrata Cham. \& Schltdl., Linnaea 3: 353 (1828). Fig. 6j-m Richardia humistrata distribui-se nos Estados Unidos, México, Perú, Argentina, Uruguai, Sul e Sudeste do Brasil, em campos e margem de estradas, ocorrendo como introduzida na África do Sul (Delprete et al. 2005; Lewis \& Oliver 1974). Em Camanducaia, foi coletada em pasto, com flores e frutos de janeiro a abril. Caracteriza-se pelo hábito herbáceo prostrado, com ramos densamente hirsutos e radicantes, dando à planta um aspecto de "tapete", estípulas fimbriadas e esquizocarpos glabros, separando-se em quatro mericarpos.

Material selecionado: Monte Verde, 24.I.2013, fl. e fr., J.A.M. Carmo et al. 112 (UEC).

38. Rudgea jasminoides (Cham.) Müll. Arg. subsp. jasminoides, Flora 59: 452 (1879)

三 Coffea jasminoides Cham., Linnaea 9: 222 (1834).

Fig. 6n,o

Ocorre em São Paulo, Minas Gerais e Paraná, em floresta de galeria, floresta estacional semidecidual, floresta ombrófila e floresta ombrófila mista (BFG 2015), podendo chegar até o Paraguai (Zappi 2003). Em Camanducaia foi coletada em subosque de floresta ombrófila densa montana e floresta ombrófila mista, com flores de outubro a novembro e frutos de dezembro a abril. Pode ser caracterizada pelas estípulas ovadas a oblongas, portando carena dorsal com apêndices numerosos, filiformes, inflorescência em tirso, laxa, cálice lobado e frutos amarelos a alaranjados.

Material selecionado: Melhoramentos, 13.VII.2012, fr., J.A.M. Carmo et al. 68 (UEC); Monte Verde, 7.XI.2001, fl., L.D. Meireles 736 (UEC).

39. Rudgea sessilis (Vell.) Müll. Arg. subsp. sessilis, Fl. bras. 6(5): 182 (1881)

$\equiv$ Psychotria sessilis Vell., Fl. Flumin.: 65 (1829).

Fig. $6 \mathrm{p}$

Ocorre em Minas Gerais, Rio de Janeiro e São Paulo, em floresta de galeria, floresta estacional semidecidual e floresta ombrófila (BFG 2015). Em Camanducaia foi coletada em subosque de mata de encosta. Encontrada com frutos de dezembro a março. Este táxon pode ser caracterizado pelas estípulas ovadas, carenada, dotadas de apêndices dorsais e marginais, domáceas na face abaxial da lâmina foliar e inflorescências em cimeiras congestas.

Material selecionado: Mata do Chico Rei, 1.395 m, 22.III.2001, fr., R.B. Torres 1419 (IAC, UEC).

\section{Discussão}

A região de Camanducaia compreende remanescentes importantes de fitofisionomias típicas de Mata Atlântica. Táxons endêmicos deste domínio fitogeográfico apresentam alguns padrões de distribuição, como (1) Cordiera concolor var. concolor, Manettia glaziovii, Manettia gracilis, Psychotria sp. (三Psychotria dusenii Standl. nom. illeg.), Psychotria suterella e Rudgea jasminoides subsp. jasminoides que distribuem-se no Sudeste e Sul do Brasil, podendo chegar até o oeste do Paraguai e/ou à província de Misiones, na Argentina. Este padrão é congruente com a delimitação da região sul da Mata Atlântica (Fiaschi \& Pirani 2009). (2) Palicourea jungiana, Palicourea rudgeoides e Psychotria niveobarbata distribuem-se no Sudeste e Sul do Brasil, apresentando populações disjuntas no estado da Bahia. A ocorrência de espécies características de regiões montanhosas da Mata Atlântica no Sudeste do Brasil já foi relatada para remanescentes de floresta montana no sul da Bahia (Amorim et al. 2009). (3) Galianthe vaginata e Psychotria beyrichiana são endêmicas da Serra 
da Mantiqueira e Serra do Mar, o que demonstra a importância dessas cadeias de montanhas para a evolução da flora e agrega valor de conservação à região.

A identificação de espécies de Rubiaceae no Brasil pode representar um desafio, tanto para especialistas quanto para leigos, devido à sua elevada diversidade e complexidade taxonômica (BFG 2015; Delprete \& Jardim 2012). O número de óvulos por lóculo do ovário é um caráter utilizado na taxonomia da família desde a sua descrição original (Jussieu 1789), bem como nos primeiros passos de chaves de identificação dicotômicas em floras e/ou sinópses regionais (Delprete et al. 2004; Delprete \& Cortés 2006; Jung-Mendaçolli 2007; Delprete 2010; Delprete et al. 2012). Em contrapartida, as CIEM possibilitam a livre de escolha de caracteres a serem analisados pelo usuário (Bittrich et al. 2012; Chrétiennot-Dinet et al. 2014), o qual pode optar pela utilização caracteres vegetativos, de maneira que estruturas ausentes no material examinado não necessariamente comprometam a realização de sua identificação. Através da utilização da CIEM aqui proposta, a maioria dos táxons (com exceção de Borreria verticillata, Coussarea contracta, Galianthe andersonii, Galianthe valerianoides, Psychotria sp. (三Psychotria dusenii Standl. nom. illeg.) e Rudgea sessilis subsp. sessilis) puderam ser identificados utilizando-se somente caracteres vegetativos. Adicionalmente, táxons que apresentam características vegetativas marcantes, como Borreria palustris (ramos conspicuamente alados, alas de margem escabra a denteada), Coccocypselum lymansmithii (lâmina foliar orbicular), Galianthe vaginata (ramos conspicuamente alados, alas de margem escabriúscula), Galium noxium (lâmina foliar trinérvea), Margaritopsis sp. (ramos achatados, costados em ambos os lados) e Randia ferox (ramos com espinhos) puderam ser identificados com somente um passo.

\section{Agradecimentos}

Os autores agradecem ao CNPq $(03 / 2012$ - 08/2012) e à Fapesp (processo 2012/09232-9, 09/2012 - 02/2014), a bolsa de Mestrado concedida ao primeiro autor; à curadoria dos herbários $\mathrm{BHCB}$, ESA, HRCB, IAC, ICN, MBM, SP e UEC; aos especialistas na família Rubiaceae, Carla Bruniera, Charlotte Taylor, Claes Persson, Elsa Cabral, Javier Florentin, Marcela Firens, Roberto Salas e Sandra Sobrado, a ajuda na identificação das espécies dos seus respectivos grupos de estudo; ao LIS (Laboratoire Informatique \& Systématique), o suporte técnico em $\mathrm{Xper}^{2}$ e Xper³; a Klei Sousa, as ilustrações; aos dois revisores, cujas críticas e sugestões contribuíram para melhoria do manuscrito.

\section{Referências}

Alvares CA, Stape JL, Sentelhas PC, De Moraes Gonçalves JL \& Sparovek G (2013) Köppen's climate classification map for Brazil. Meteorologische Zeitschrift 22: 711-728.

Amorim AM, Jardim JG, Lopes MMM, Fiaschi P, Borges RAX, Perdiz RO \& Thomas WW (2009) Angiosperms of Montane Forest areas in southern Bahia, Brazil. Biota Neotropica 9: 313-348.

Barbosa MRV (2007) Guettarda. In: Wanderley MGL (coord.) Flora fanerogâmica do estado de São Paulo. Instituto de Botânica, São Paulo. Vol. 5, pp. 346-348.

Becker CG, Rodriguez D \& Zamudio KR (2013) The Brazilian Adirondacks? Science 340: 428.

BFG - The Brazil Flora Group (2015) Growing knowledge: an overview of seed plant diversity in Brazil. Rodriguésia 66: 1085-1113.

Bittrich V, Souza CSD, Coelho RLG, Martins MV, Hopkins MJG \& Amaral MCE (2012) An interactive key (Lucid) for the identifying of the genera of seed plants from the Ducke Reserve, Manaus, AM, Brazil. Rodriguésia 63: 55-64.

Burger W \& Taylor CM (1993) Family 202: Rubiaceae. In: Burger W. Flora Costaricensis. Vol. 33. Fieldiana, Botany, New Series, Chicago. Pp. 1-333.

Cabral EL (2009) Revisión Sinóptica de Galianthe subgen. Galianthe (Rubiaceae: Spermacoceae), con una Sección Nueva. Annals of the Missouri Botanical Garden 96: 27-60.

Cabral EL, Miguel LM \& Salas RM (2011) Dos especies nuevas de Borreria (Rubiaceae), sinopsis y clave de las especies para Bahia, Brasil. Acta Botanica Brasilica 25: 255-276.

Carmo JAM, Salas RM \& Simões AO (2016) An updated description of Galianthe vaginata (Spermacoceae, Rubiaceae), a species endemic to the Serra da Mantiqueira and Serra do Mar, Southeast Brazil. Phytotaxa 258: 89-94

Chrétiennot-Dinet MJ, Desreumaux N \& Vignes-Lebbe R (2014) An interactive key to the Chrysochromulina species (Haptophyta) described in the literature. Phytokeys 34: 47-60.

Costa CB (2004) Revisão taxonômica de Coccocypselum P. Br. Tese de Doutorado. Universidade de São Paulo, São Paulo. 133p.

Costa CMR, Hermann G, Martins CS, Lins LV \& Lamas IR (orgs.) (1998) Biodiversidade em Minas Gerais: um atlas para sua conservação. Fundação Biodiversitas, Belo Horizonte. 94p.

Davis AP, Govaerts R, Bridson DM, Ruhsam M, Moat J \& Brummitt NA (2009) A global assessment of distribution, diversity, endemism, and taxonomic 
effort in the Rubiaceae. Annals of the Missouri Botanical Garden 96: 68-78.

Delprete PG (2010) Rubiaceae - Parte 1: introdução, gêneros a-h. In: Rizzo JA (coord.) Flora dos estados de Goiás e Tocantins. Vol. 40. IRD/UFG, Universidade Federal de Goiás, Goiânia. 580p.

Delprete PG \& Jardim JG (2012) Systematics, taxonomy and floristics of Brazilian Rubiaceae: an overview about the current status and future challenges. Rodriguésia 63: 101-128.

Delprete PG \& Cortés R (2006) A synopsis of the Rubiaceae of the states of Mato Grosso and Mato Grosso do Sul, Brazil, with a key to genera, and a preliminary species list. Revista de Biologia Neotropical 3: 13-96.

Delprete PG, Persson CH, Souza EB, Salas RM, Cabral EL \& Costa CB (2012) Rubiaceae. In: Cavalcanti TB \& Dias EBA (2012) Flora do Distrito Federal, Brasil. Vol. 10. Embrapa, Brasília. 340p.

Delprete PG, Smith LB \& Klein RB (2004) Rubiáceas. Vol. I - gêneros de a-g: 1. Alseis até 19. Galium. (com observações ecológicas por Klein R, Reis A \& Iza O). In: Reis A (ed.) Flora ilustrada catarinense. Herbário Barbosa Rodrigues, Itajaí. Pp. 1-344.

Delprete PG, Smith LB \& Klein RB (2005) Rubiáceas. Vol. 2 - Gêneros de G-Z: 20. Gardenia até 46. Tocoyena (com observações ecológicas por Klein R, Reis A \& Iza O). In: Reis A (ed.) Flora ilustrada catarinense. Herbário Barbosa Rodrigues, Itajaí. Pp. 345-843.

Fiaschi P \& Pirani JR (2009) Review of plant biogeographic studies in Brazil. Journal of Systematics and Evolution 47: 477-496.

França GS \& Stehmann JR (2004) Composição florística e estrutura do componente arbóreo de uma floresta altimontana no município de Camanducaia, Minas Gerais, Brasil. Revista Brasileira de Botânica 27: 19-30.

Gomes M (2003) Reavaliação taxonômica de algumas espécies dos gêneros Coussarea Aubl. e Faramea Aubl. (Rubiaceae, tribo Coussareae). Acta Botanica Brasilica 17: 449-466.

Govaerts R, Andersson L, Robbrecht E, Bridson D, Davis A, Schanzer I \& Sonke B (2006) World checklist of Rubiaceae. The board of trustees of the Royal Botanic Gardens, Kew. Disponível em $<$ http://www.kew.org/wcsp/rubiaceae/>. Acesso em 21 dezembro 2015.

Judkevich MD, Salas RM \& Gonzalez AM (2015) Revisión de Randia (Rubiaceae) en Argentina, taxonomía y morfoanatomía. Boletín de la Sociedad Argentina de Botánica 50: 607-625.

Jung-Mendaçolli SL (2007) Rubiaceae. In: Wanderley MGL (coord.) Flora fanerogâmica do estado de São Paulo. Instituto de Botânica, São Paulo. Vol. 5, pp. 259-460.

Jussieu AL de (1789) Rubiaceae. Genera Plantarum secundum ordines naturales disposita, juxta methodum in horto regio parisiensis exaratum. Herissant \& Barrois, Paris. Pp. 196-210.

Macias L (1988) Revisão taxonômica do gênero Posoqueria Aubl. (Rubiaceae). Dissertação de Mestrado. Universidade Estadual de Campinas, Campinas. Pp. 165.

Macias L (1998) Estudos taxonômicos do gênero Manettia Mutis ex L. nom. cons. (Rubiaceae) no Brasil, Paraguai, Argentina e Uruguai. Tese de Doutorado. Universidade Estadual de Campinas, Campinas. Pp. 356.

Meireles LD, Kinoshita LS \& Shepherd GJ (2014) Composição florística da vegetação altimontana do distrito de Monte Verde (Camanducaia, MG), Serra da Mantiqueira Meridional, Sudeste do Brasil. Rodriguésia 65: 831-856.

Morrone JJ (2006) Biogeographic areas and transition zones of Latin America and the Caribbean Islands based on panbiogeographic and cladistic analyses of the entomofauna. Annual Review of Entomology 51: 467-494.

Müller J (1881) Rubiaceae. In: Martius CFP von, Eichler AW \& Urban I. Flora brasiliensis. Leipzig, Munchen, Wien. Vol. 6, pars 5, pp. 1-410.

Myers N, Mittermeier RA, Mittermeier CG, da Fonseca GAB \& Kent J (2000) Biodiversity hotspots for conservation priorities. Nature 403: 853-858.

Oliveira-Filho AT \& Fontes MAL (2000) Patterns of floristic differentiation among Atlantic forests in Southeastern Brazil and the influence of climate. Biotropica 32: 793-810.

Perret M, Chautems A \& Spichiger R (2006) Dispersalvicariance analysis in the tribe Sinningieae (Gesneriaceae): a clue to understanding biogeographical history of the Brazilian Atlantic Forest. Annals of the Missouri Botanical Garden 93: 340-358.

Pinto-da-Rocha R \& Silva MB (2005) Faunistic similarity and historic biogeography of the harvestmen of Southern and Southeastern Atlantic rain forest of Brazil. The Journal of Arachnology 33: 290-299.

Prance GT (1982) A review of the phytogeographic evidences for pleistocene climate changes in the neotropics. Annals of the Missouri Botanical Garden 69: 594-624.

Radford AE, Dickinson WC, Massey JR \& Bell CR (1974) Vascular plant systematics. Harper \& Row, New York. 891p.

Ribeiro MC, Metzger JP, Martensen AC, Ponzoni FJ \& Hirota MM (2009) The brazilian Atlantic forest: How much is left, and how is the remaining forest distributed? Implications for conservation. Biological Conservation 142: 1141-1153.

Schumann K (1888) Rubiaceae. In: Martius CFP von, Eichler AW \& Urban I. Flora brasiliensis. Leipzig, Munchen, Wien. Vol. 6, pars 6, pp. 5-102.

Saout S, Hoffmann M, Shi Y, Hughes A, Bernard C, Brooks TM, Bertzky B, Butchart SHM, 
Stuart SN, Badman T \& Rodrigues ASL (2013) Conservation. Protected areas and effective biodiversity conservation. Science 342: 803-805.

Silva JMC, Sousa MC \& Castelletti CHM (2004) Areas of endemism for passerine birds in the Atlantic forest, South America. Global Ecology and Biogeography 13: 85-92.

Sobral M \& Stehmann JR (2009) An analysis of new angiosperm species discoveries in Brazil (19902006). Taxon 58: 227-232.

Souza EB, Cabral EL \& Zappi DC (2010) Revisão de Mitracarpus (Rubiaceae - Spermacoceae) para o Brasil. Rodriguésia 61: 319-352.
Taylor CM (2005) Margaritopsis (Rubiaceae, Psychotrieae) in the Neotropics. Systematics and Geography of Plants 75: 161-177.

Taylor CM (2015) Rubiacearum Americanarum Magna Hama XXXIV: the new group Palicourea sect. Tricephalium with eight new species and a new subspecies (Palicoureeae). Novon 23: 452-478.

Ung V, Dubus G, Zaragüeta-Bagils R \& VignesLebbe R (2010) Xper²: introducing e-taxonomy. Bioinformatics 26: 703-704.

Zappi DC (2003) Revision of Rudgea (Rubiaceae) in Southeastern and Southern Brazil. Kew Bulletin 58: 513-596.

\section{Lista de coletores}

Anderson LO 00/35 (17). Carmo JAM 1 (22), 2 (3), 3 (36), 4 (3), 5 (3), 6 (25), 7 (36), 8 (7), 9 (15), 10 (7), 11 (22), 12 (3), 13 (36), 14 (26), 15 (17), $16(3), 17$ (6), $18(3), 19(25), 20$ (1), 21 (1), 22 (6), 23 (36), 24 (13), 26 (1), $27(25), 28(2), 29(2), 30(36), 31(2), 32(2), 33(3), 34(15), 39$ (15), 42 (15), 43 (5), 44 (6), 45 (5), 46 (6), 47 (15), 49 (6), 50 (12), 52 (5), $56(20), 59$ (27), 60 (27), 61 (25), 62 (25), 65 (15), 66 (5), $68(38), 71$ (13), $72(13), 73(6), 74(13), 77(15), 104(33), 105(13), 106(33), 107(1), 110(36), 111(4), 112(37) 114(27), 115(27), 116(27), 117(27), 118$ (28), $119(30), 120(16), 121(30), 122(30), 123(30), 124(30), 125(4), 126(2), 127$ (7), 128 (7), 129 (7), 130 (7), 131 (27), $132(2), 133(23)$, 134 (23), 135 (27), $136(30), 137$ (30), 138 (6), 140 (13), 141 (13), 142 (13), 143 (1), 146 (5), 153 (33), $154(33), 155$ (15), $158(5), 159(16), 160$ (24), 161 (38), 162 (38), 195 (19), 196 (19), 403 (8). Costa ACM 126 (35). Costa LV (29). França GS 91 (26), 120 (6), 190 (26), 198 (26), 204 (26), 233 (26), 236 (9), 254 (20), 271 (9), 275 (33). Gouvea LSK 785 (9). Kamino LHY 8 (15), 26 (26), 33 (33), 37 (33), 39 (6), 46 (20), 49 (32), 53 (9), 57 (32), 60 (28). Kinoshita LS 300 (29). Leitão-Filho H 10681 (10). Lewinson T 40 (5), 54 (6). Lombardi JA 4376 (33), 4400 (31). Longhi-Wagner I 2875 (5). Mathes LAF 664 (10). Meireles LD 4 (6), 278 (6), 331 (17), 399 (26), 414 (31), 615 (6), 674 (33), 703 (11), 718 (33), 721 (1), 730 (5), 736 (38), 748 (38), 773 (1), 803 (14), 804 (5), 860 (1), 956 (38), 957 (26), 962 (22), 1065 (26), 1071 (17), 1202 (38), 1327 (6), 1330 (33), 3387 (37). Mota RC 1261 (6), 1262 (15). Sartori A 26578 (21). Stehmann JR 2581 (33), 2987 (15). Torres RB 737 (38), 766 (38), 767 (28), 829 (5), 850 (28), 854 (35), 880 (38), 884 (28), 908 (26), 914 (33), 924 (6), 958 (28), 968 (28), 972 (32), 993 (38), 1024 (6), 1025 (1), $1028(5), 1032$ (33), 1040 (26), 1141 (9), 1043 (26), $1176(4), 1185(38), 1203(15), 1226(38), 1236(9), 1237(38), 1265(38), 1346(18), 1347$ (18), 1360 (38), 1413 (38), 1416 (21), 1418 (34), 1419 (39), 1452 (38), 1468 (34), 1469 (38), 1473 (18), 1474 (39). Yamamoto LF 1791 (26). 